الا لاتل البيئية لصخور الحجر الجيري الستروماتولايتي في تكوين بارسرين لمقاطع سطحية مختارة في شمال شرقي العرلق الجيري

رافع أبراهيم الحميدي

موج علي البدراني

$$
\begin{aligned}
& \text { قسم علوم الأرض } \\
& \text { كلية العلوم } \\
& \text { جامعة الدوصل } \\
& \text { (تاريخ الاستلام 2019/5/7 تاريخ القبول 2019/7/25) }
\end{aligned}
$$

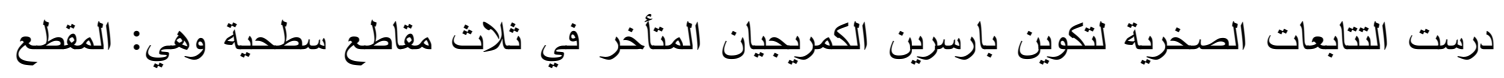

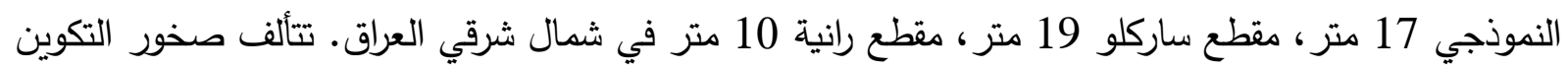

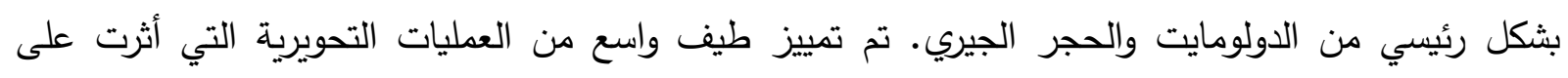

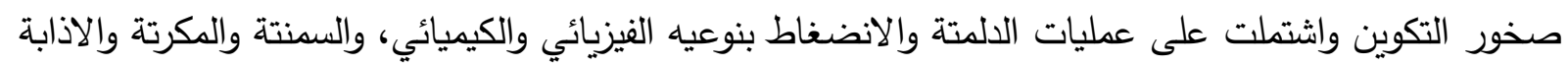

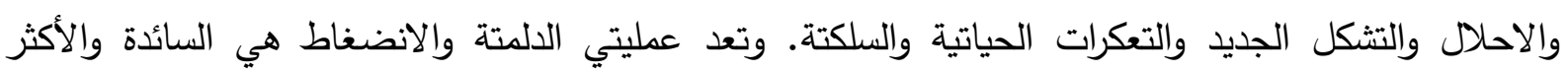

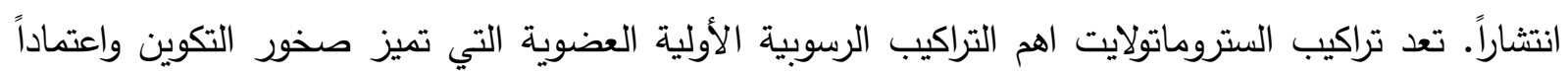

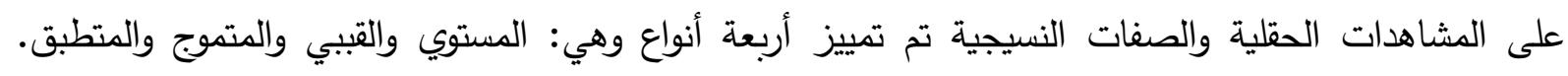

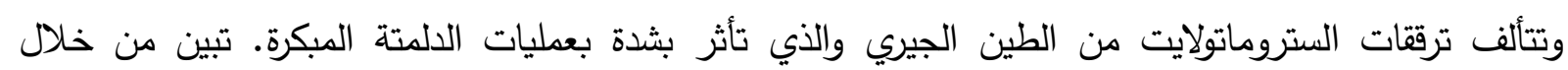

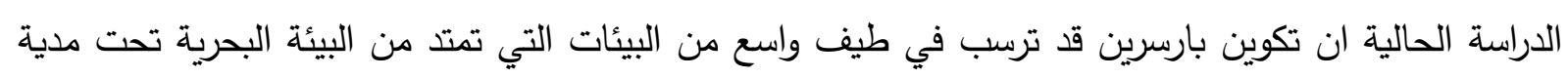
الضحلة الى البيئة بين الددية ومن ثم البيئة فوق المدية.

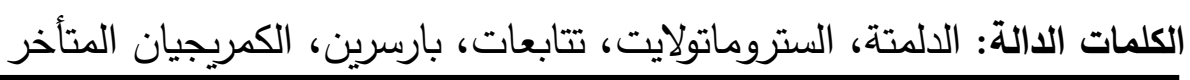

\title{
Environmental Criteria of Stromatolitic Limestones in The Barsrain Formation from Surface Sections, Northeastren Iraq
}

\author{
Mauj Ali Hussein Al-Badrani \\ Department of Geology \\ College of Science \\ Mosul University
}

Rafee Ibraheem Al-Humaidi

\begin{abstract}
The rock successions of Barsarin Formation Late Kimmeridgian was studied at three surface sections the type section "17m", Sarglu "19m" and Rania "10m"; northeastern Iraq. The detailed sedimentological study reveals that the formation consists mainly of dolomite and dolomitic limestones. A wide spectrum of diagenetic - processes are recognized in the rock successions; these are dolomitization, compaction, cementation, micritization, dissolution, replacement, neomorphism and
\end{abstract}


silisification. By the far, dolomitization and compaction are the most common and widespread processes. Stromatolites are the dominant primary sedimentary structures in this Formation. Based on field observation and textural characteristics four stromatolite types are distinguished: planar, wavy, domal, and bedded. They are normally formed by carbonates (lime muds) and extensively suffered early dolomitization.

Keywords: dolomitization, Stromatolites, Successions, Barsarin, Late Kimmeridgian.

\section{|لمقدمة}

تقع منطقة الدراسة في شمال شرقي العراق في محافظتي السليمانية واربيل، حيث المكثف النموذجي High Folded ) للتكوين. أما تكتونياً فكانت منطقة الدراسة، تقع منطقة الدراسة ضمن نطاق الطيات العالية ولية (Zone للرصيف غير المستقر (Unstable Shelf) حسب (Jassim and Buday,2006) الثكل (1). حدد (Jassim and Buday,2006)

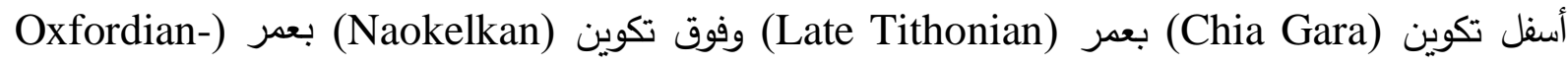
Kimmeridgian النموذجي لهذا التكوين في وادي بارسرين، قرب قرية بارسرين، شرق مدينة راوندوز في نطاق الطيات العالية، شمال شرق العراق، وتحديداً عند خط عرض (36॰37'13"N)؛ وخط طول (44×39'18"E). ويبلغ سمك التكوين في المقطع النموذجي حوالي (m m). وقد ذكر ان التكوين يتألف من طبقات الحجر الجيري والحجر الجيري المتدلمت التي تحتوي على عقد من الصوان، فضلاً على احتواء التكوين على بعض الطبقات الملتوية وطبقات من صخور البريشيا. ويقع مقطع الدراسة الثاني للتكوين في منطقة ساركلو قرب قرية ساركلو في ناحية سورداش في محافظة السليمانية تقريباً عند تقاطع إحداثيات خطوط العرض (35॰52'5.9"N) خطوط الطول

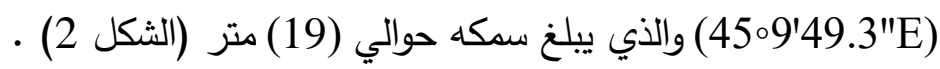

يتألف التكوين في هذا المقطع من الحجر الجيري والحجر الجيري المتدلمت الحاوي على عروق من الكالسايت وطبقات من صخور البريشيا وتراكيب الستروماتولايت. في حين يقع المقطع الثالث للتكوين في منطقة رانية (ناحية رانية قرب قرية هنجيرة) في محافظة السليمانية تقريباً عند تقاطع إحداثيات خطوط العرض فئن (36॰17'12.9"N) هذا المقطع من الحجر الجيري والحجر الجيري المتدلمت ذو تطبق سميك الحاوي على عقد من الصوان وتراكيب الستروماتولايت.

نظراً لهيمنة أنواع مختلفة من تراكيب الستروماتولايت ضمن صخور التكوين، فأن هدف الدراسة الحالية هو تسليط الضوء على هذه التراكيب وذلك بالاعتماد على الدلائل الحقلية والبتروغرافية وصولاًا الى التعرف على أنواع لتوني الستروماتولايت حسب التصانيف المعتمدة وعلى ادلتها البيئية.

\section{طرائق البحث}

تمثلت الدراسة الحقلية بالوصف الدقيق للمقاطع الصخرية المنكثفة، متضمناً الوصف الصخري الدقيق ومتابعة كافة الظواهر والمعالم الحقلية وتراكيب الستروماتولايت والتغيرات الظاهرة على المكاشف الصخرية. كما 
تضمنت تحديدا لطبيعة حدود التماس السفلي والعلوي للتكوين، تم نمذجة (84) عينة صخرية لغرض تهيئة الثرائح الرقيقة الخاصة لتشخيص المكونات البتروغرافية حيث تم إعداد (58) شريحة صخرية في ورشة قسم علوم الأرض ودائرة المسح الجيولوجي في بغداد.

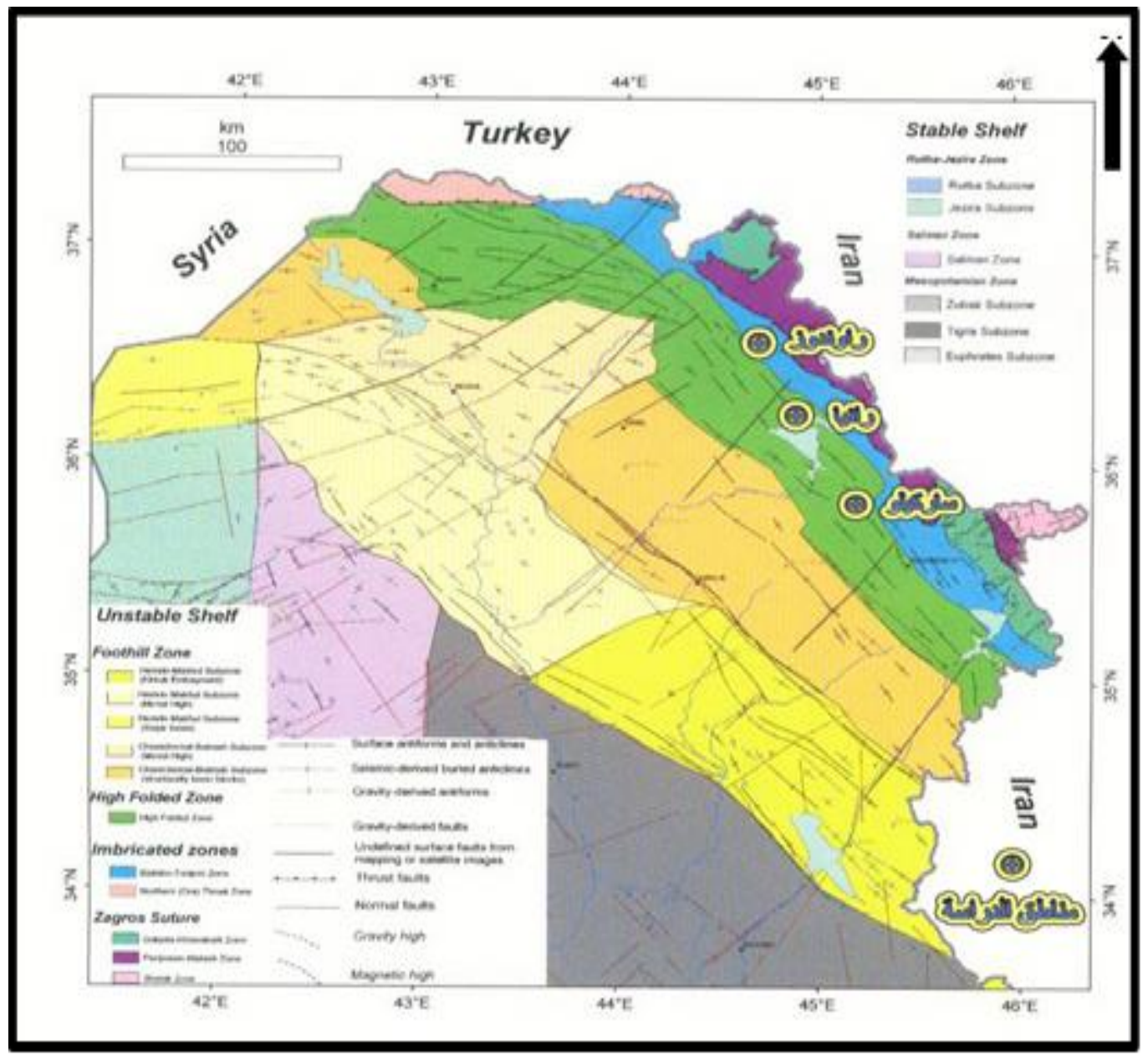

الثكل 1: خارطة تكتونية لثمالي العراق موضحاً عليها مو اقع منطقة الدر اسة ( Jassim and

.(Buday,2006

\section{الطباقية}

تتكشف تتابعات تكوين بارسرين في منطقة راوندوز ورانية وسـاركلو شمال شرقي العراق، في المقطع النموذجي (الثكل 3) يحد التكوين من الأسفل وبصورة متوافقة تتابعات تكوين ناوكليكان، أذ تتجلس ترسبات تكوين بارسرين بصورة مباشرة فوق طبقة من السجيل بنية اللون متعاقبة مع حجر جيري متدلمت رمادي اللون ذو تطبق نحيف مع ظهور طبقات رقيقة بيضاء تعود لتكوين ناوكليكان، يعقبها ظهور تكوين بارسرين الذي يتألف

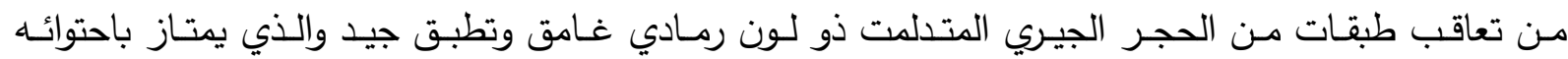
على Collapse breccia صورة (1) ويحتوي التكوين على تعاقبات الحجر الجيري ذو التطبق المستوي صورة

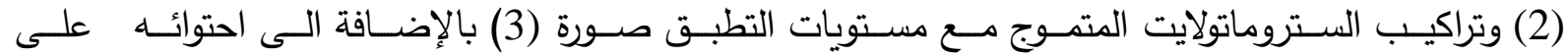
الستروماتولايت القببي صورة (5-4) وعلى طبقات من السجيل ذو اللون الأسود والتي تمتاز بظاهرة التصفح 
اما في مقطع ساركلو الشكل (4)، تتجلس ترسبات تكوين بارسرين بصورة مباشرة فوق طبقة من السجيل ذو اللون الغامق ويمتاز بانه متصفح تابعة لتكوين ناوكليكان، يعقبها ظهور تكوين بارسرين الذي يتألف من بن طبقات الحجر الجيري والحجر الجيري المتدلمت ذو تطبق نحيف ولون رمادي غامق ومحتوى عالي من عروق

الكالسايت بالإضافة إلى احتوائها على تراكيب الستروماتولايت المستوي والمتطبق الصورة (6). امـا في مقطع رانيـة الثكل (5)، تتجلس ترسبات تكوين بارسرين بصورة مباشرة فوق طبقه رقيقة من السجيل بني غامق اللون، يعقبها ظهور تكوين بارسرين الذي يتألف من طبقات من الحجر الجيري والحجر

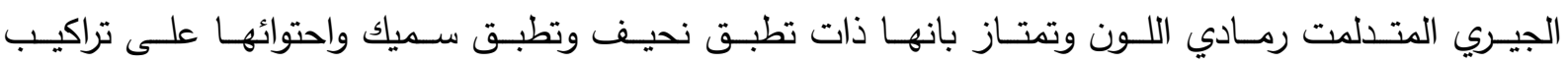
الستروماتولايت الممتوج صورة (7) وعقد من الصوان.
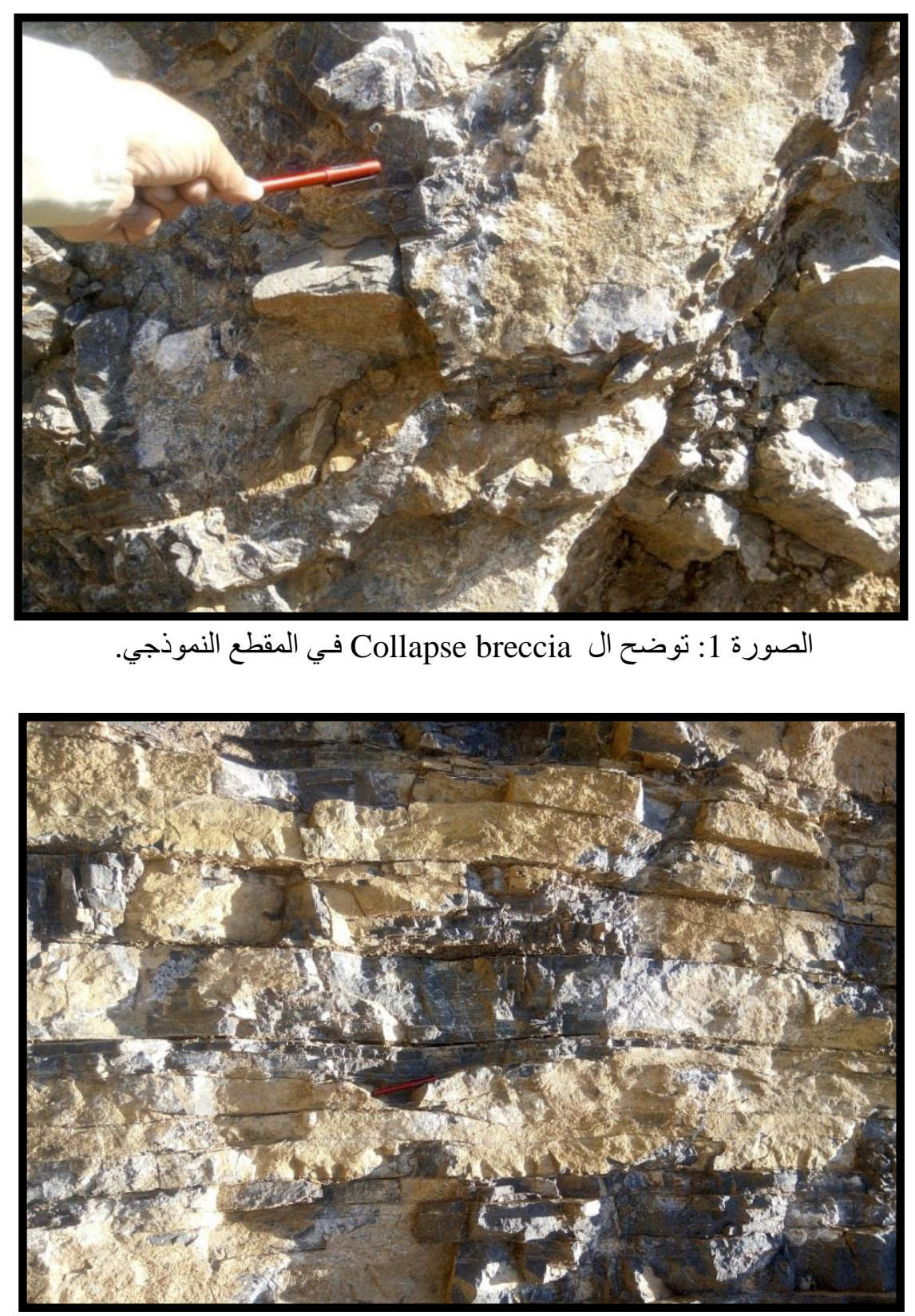

الصورة 2: توضح التطبق الجيد في المقطع النموذجي. 


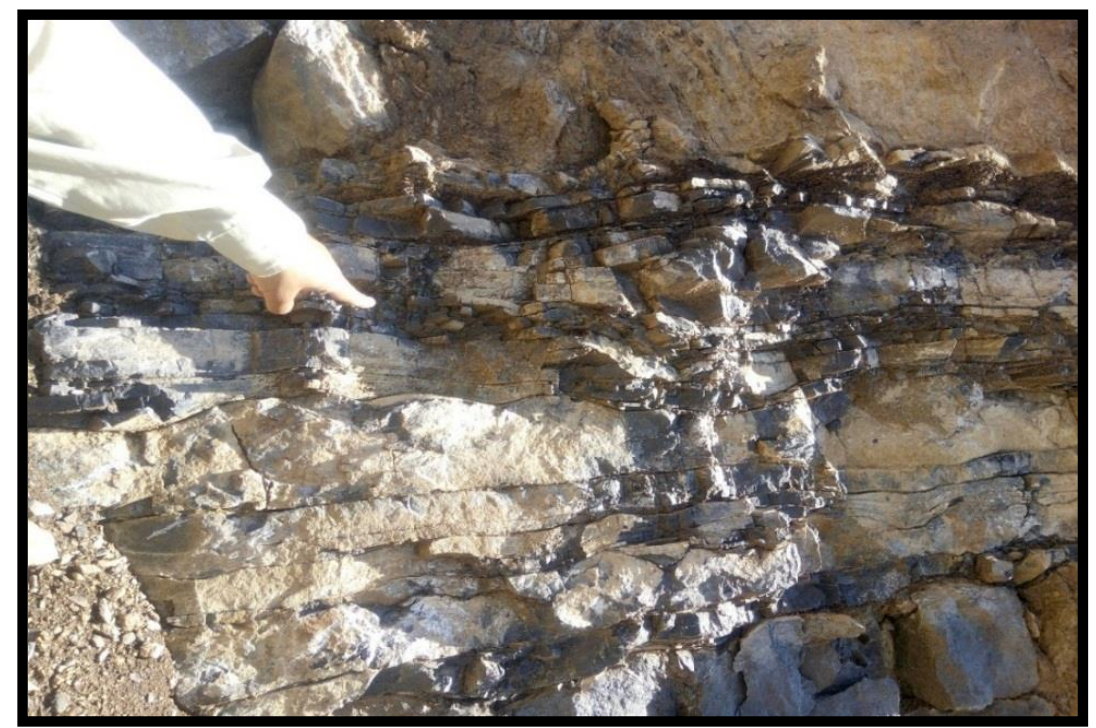

الصورة 3: توضح الستروماتو لايت المتموج مع مسنو يات التطبق في التكوين في المقطع النموذجي.

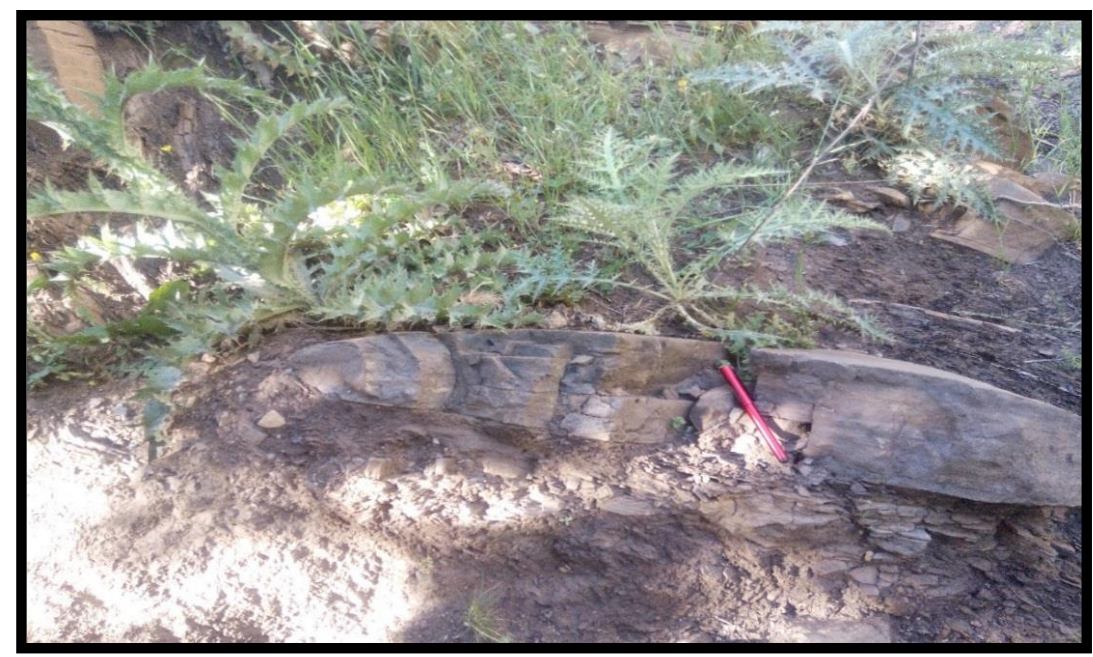

الصورة 4: توضح الستروماتولايت القببي منظر عمودي في المقطع النموذجي.

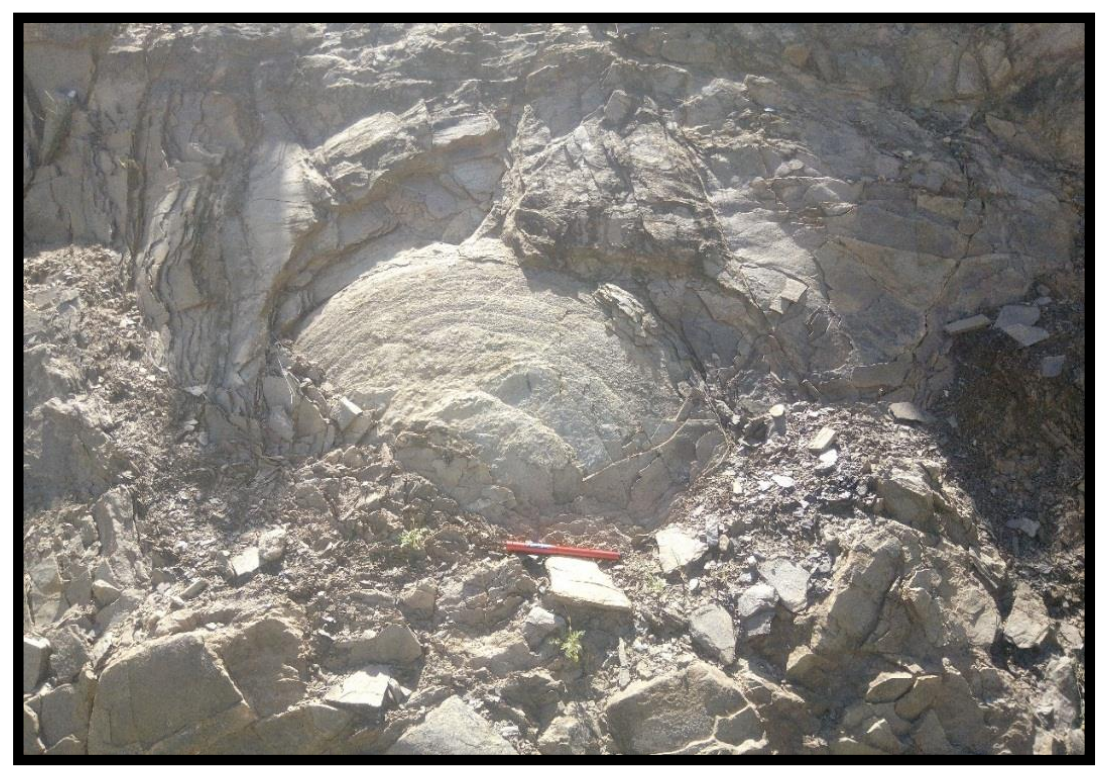

الصورة 5: توضح الستروماتولايت القببي منظر سطحي في المقطع النموذجي. 


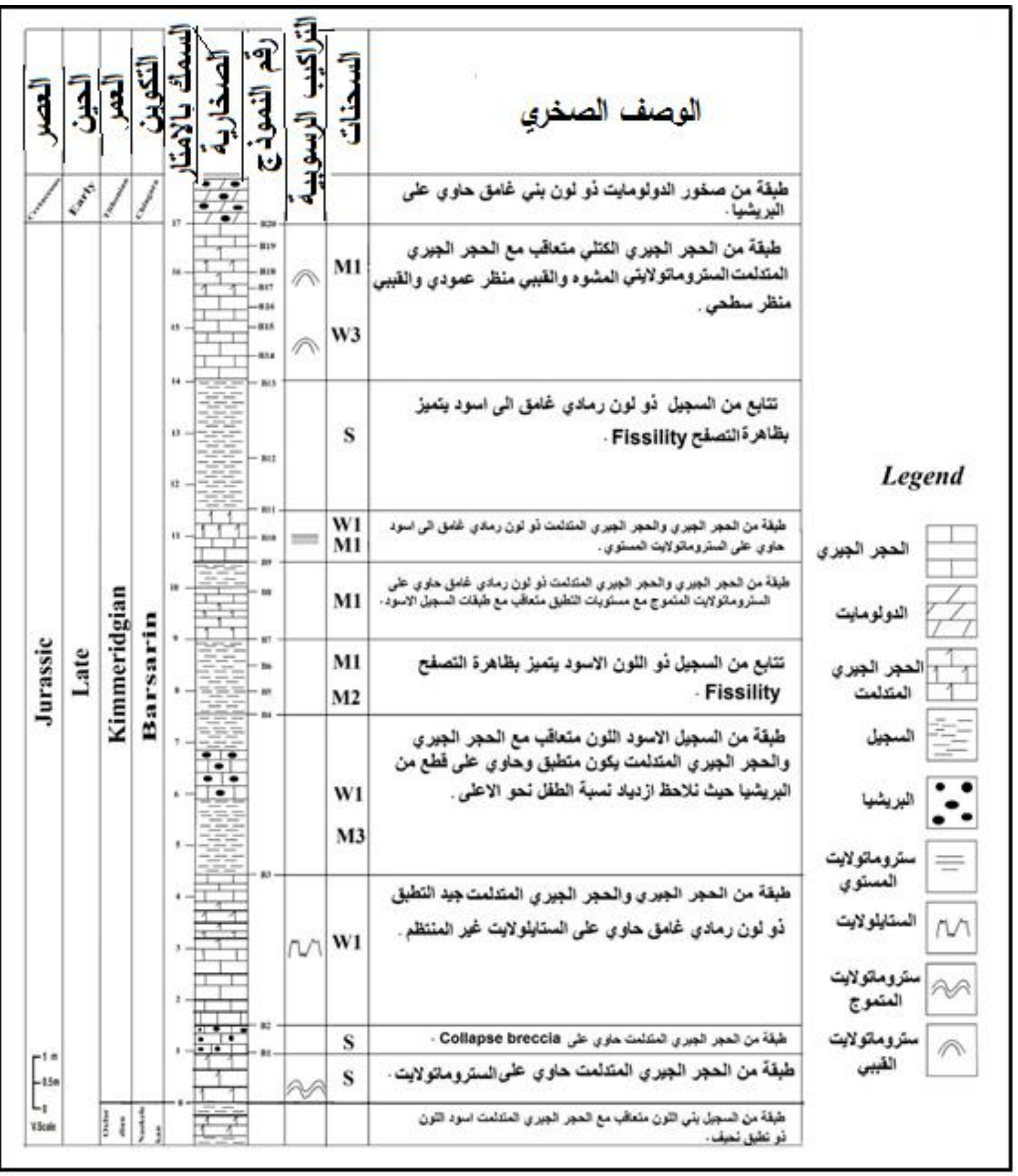

الثكل 3: يوضح العمود الطباقي لتكوين بارسرين في المقطع النموذجي. 


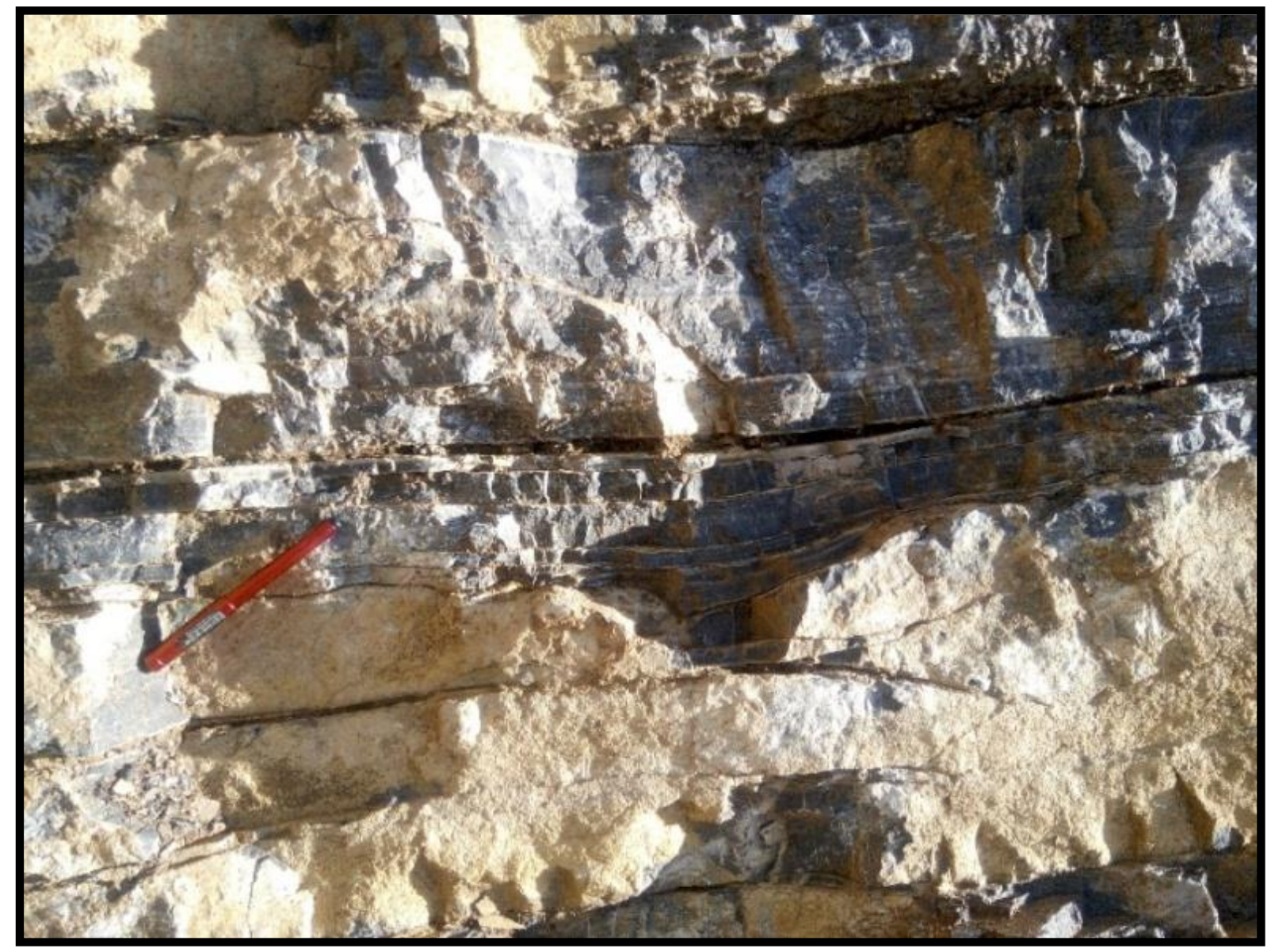

الصورة 6: توضح الستروماتولايت المتطبق والمستوي في مقطع ساركلو.

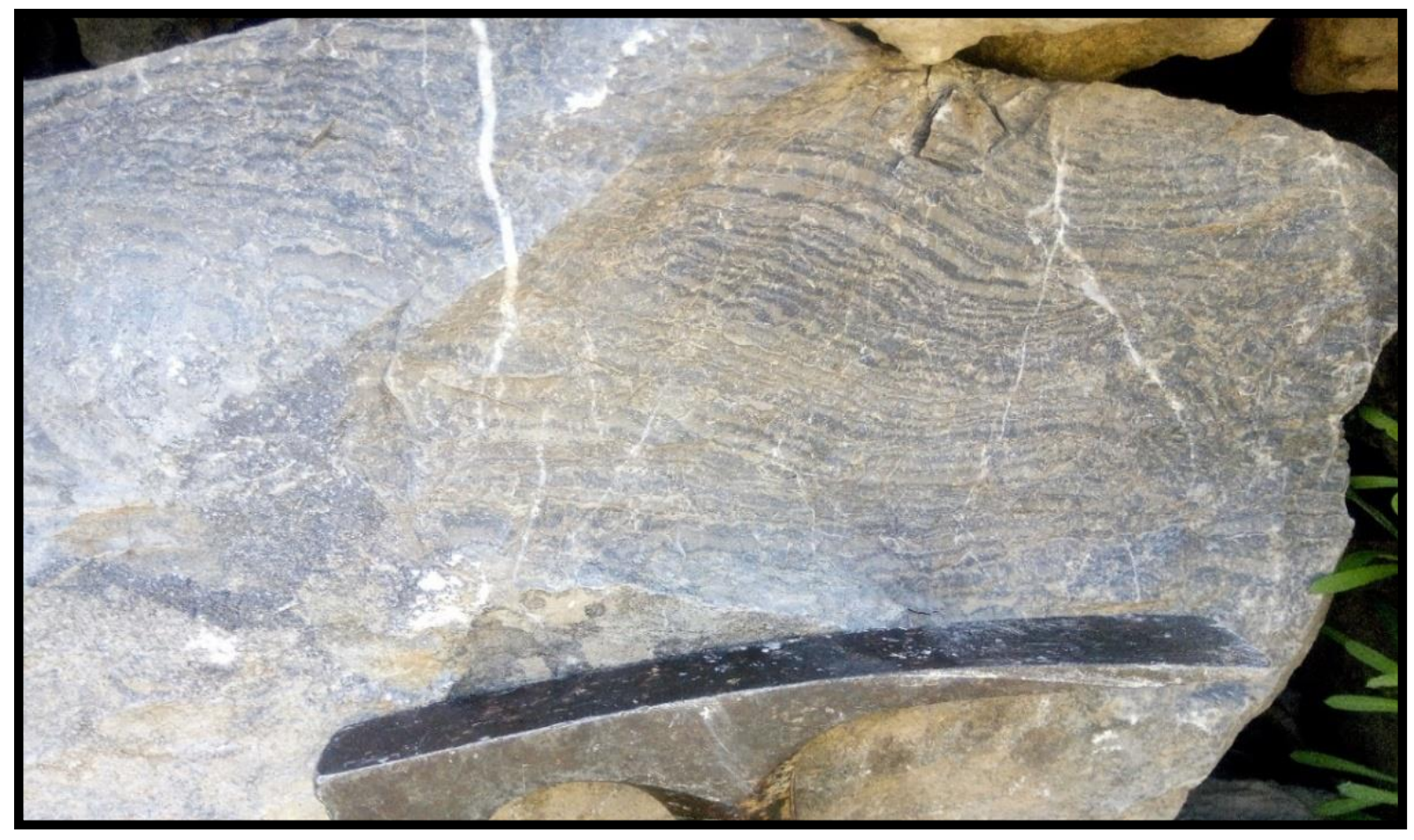

الصورة 7: توضح الستروماتولايت المتموج في مقطع رانية. 


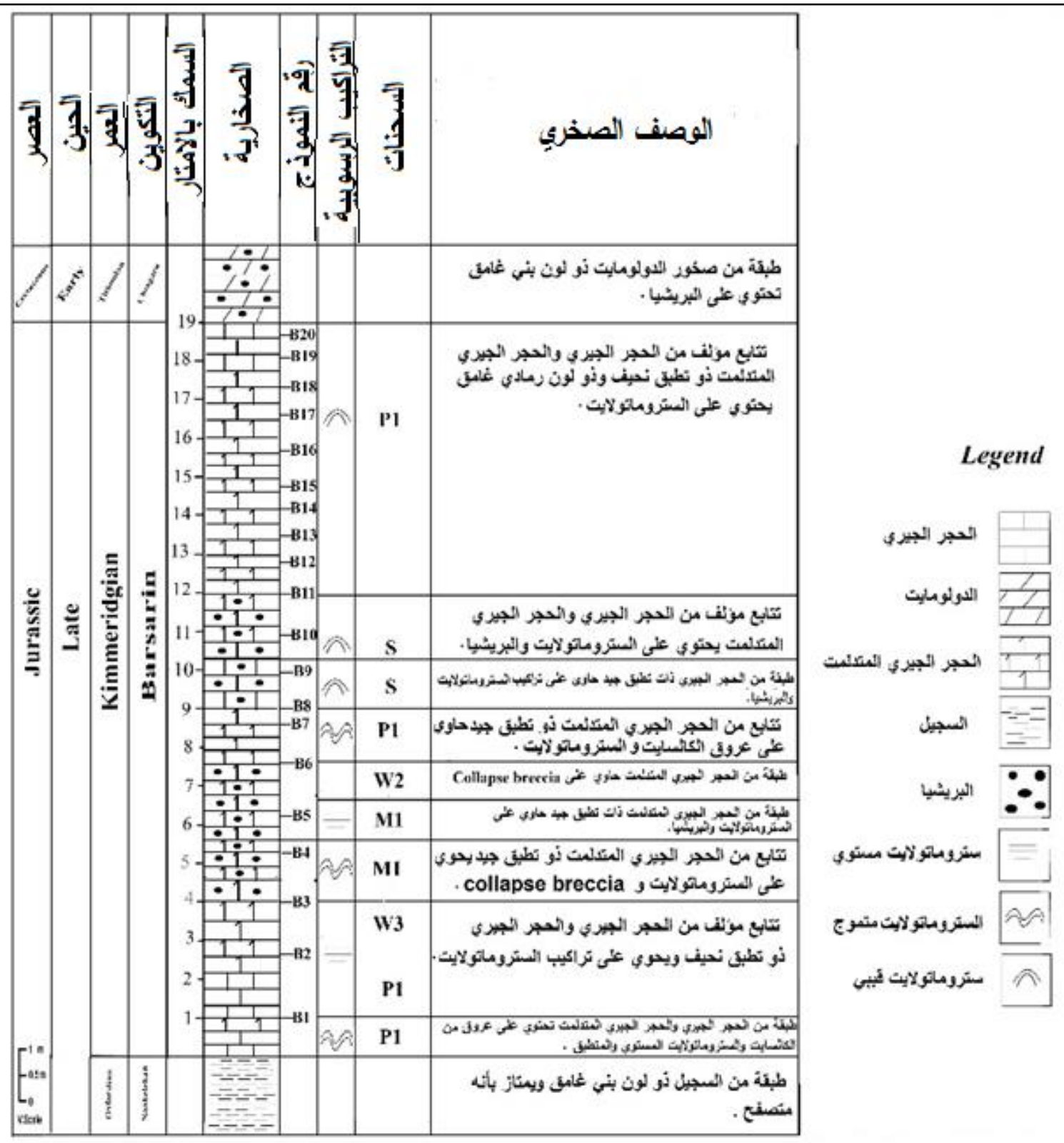

الثكل 4: يوضح العمود الطباقي لتكوين بارسرين في مقطع ساركلو. 


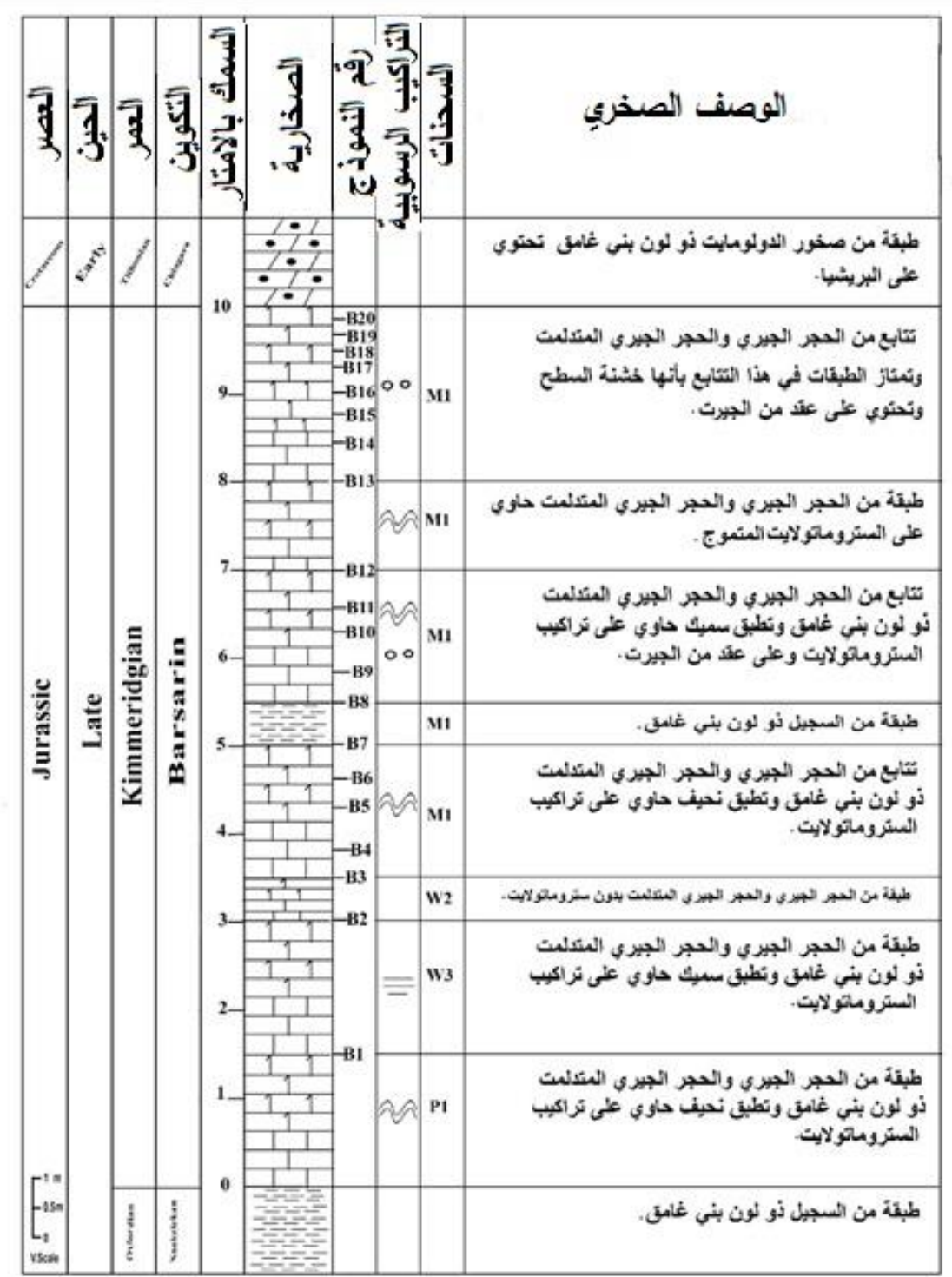

Legend

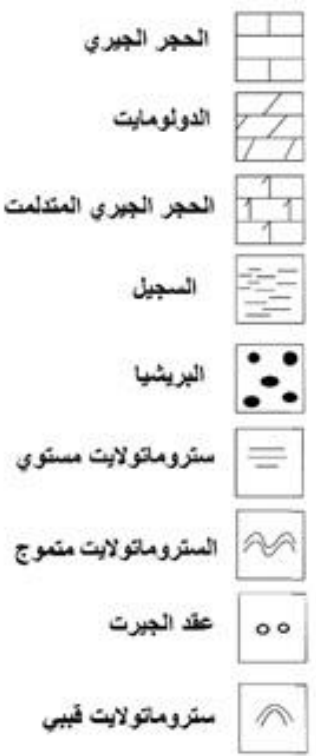

الثكل 5: يوضح العمود الطباقي لتكوين بارسرين في مقطع رانية. 


\section{البتروغرافية وإلعمليات التحويرية}

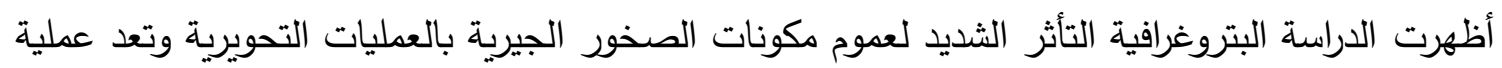

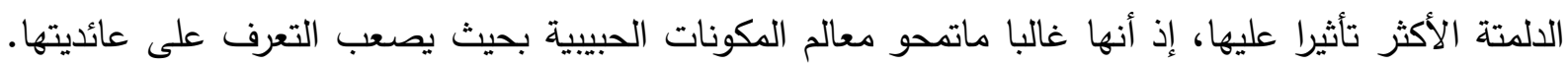

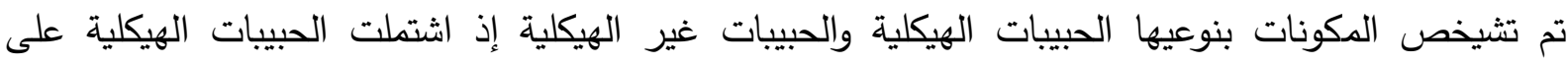

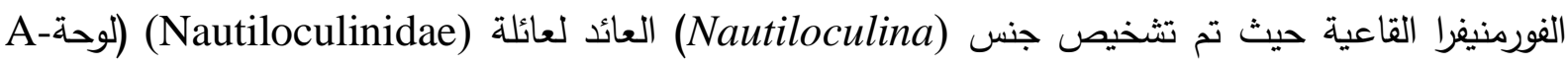

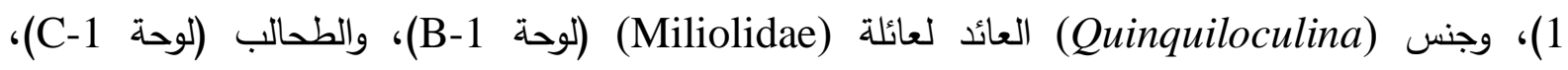
والرخويات صنف فأسية القدم (لوحة D-1)، اما الحبيات غير الهيكلية اشتملت على الدمالق (لوحة E-1) والفتاتات الصخرية بنوعيها الفتاتات الداخلية والفتاتات الخارجية (لوحة F-1). فضلا عن تأثير الدلمتة على هذه

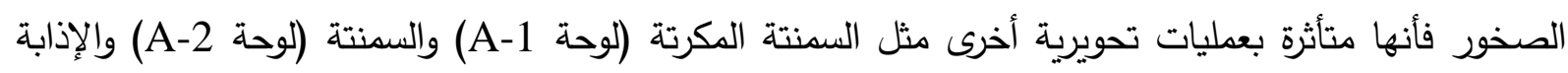

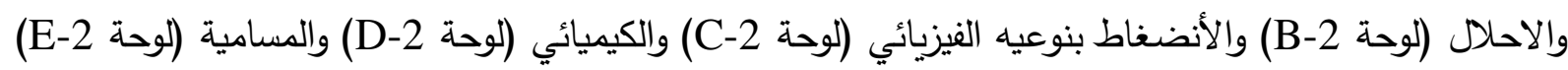

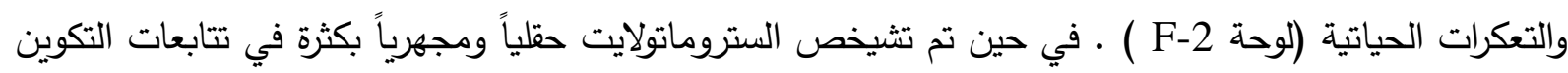

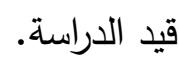

\section{تراكيب الستروماتولايت}

سجلت الدراسة الحالية ظهوراً مميزاً للطحالب الخضر المزرقة على هيئة حصران طحلبية مكونـة مـا يعرف بالستروماتولايت (Stromatolite) وهي تراكيب رسوبية عضوية تتثكل بواسطة اجتذاب او ترسيب الرئي

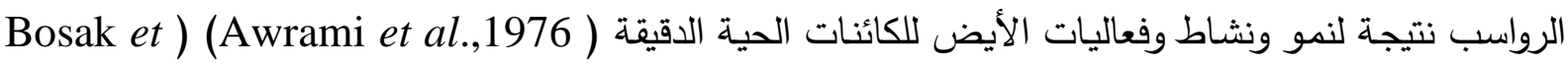

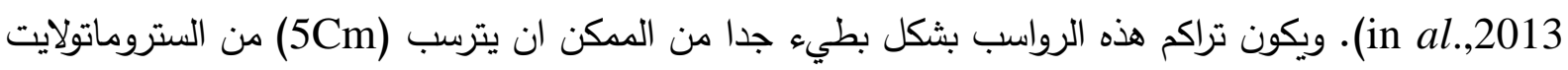

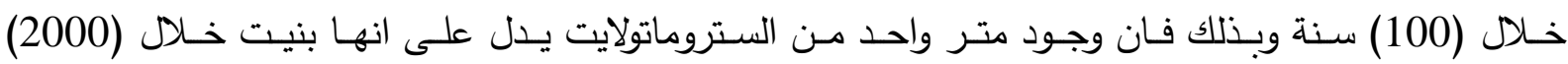

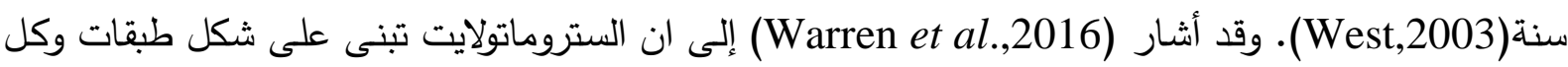

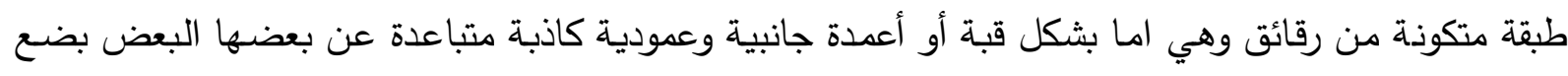

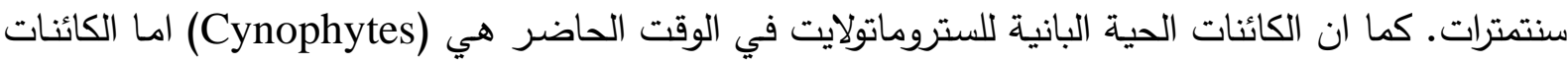

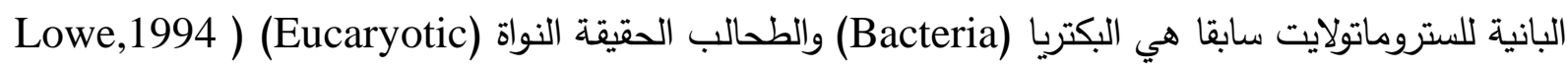
and Grotzinger and Rothman,1996). وقد اشار (West,2003) في معرض دراسته للحجر الجيري (B) لمنطقة (Hard cap) إلى ان الستروماتولايت يشيع ضمن الحجر الجيري بدرجة واضحة وان هذه التراكيب

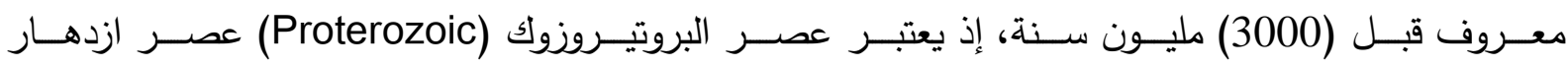

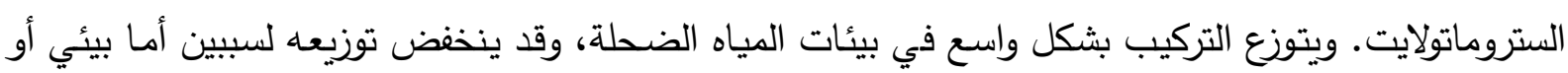
حياتي (Riding,1994).

كما ويرتبط تكوين تراكيب الستروماتولايت بتطور وانتثار الكائنات المتعددة الخلايا (Metazoans)

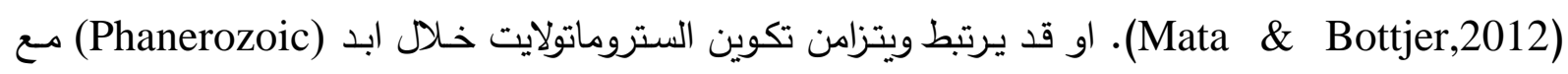
دورات تقدم وتراجع البحر كما أشار (Meyers \& Peters,2011). 
وتثير معظم الدراسات إلى أن ظروف تكون الستروماتولايت يمكن أجمالها بما يأتي: -A بيئة مستقرة تساعد على نمو الكائنات الحية الدقيقة المكونة للستروماتولايت. - معدل نمو الكائنات الحية الدقيقة اكثر من معدل استهلاكها من قبل كائنات اخرى التي تقتات عليها مثل بطنيـة القدم (Gastropoda). حيث يجب ان ينمـو الستروماتولايت ملتحمـا بسرعة حتى لا يتحطم بواسطة ثقوب وحفر الاحياء وبنفس الوقت لحماية نفسه من التآكل بواسطة عوامل كيميائية وميكانيكية

(West,2003; Walter,1976)

معدل ترسيب كـافي لبنـاء هيكل صـلب يعمل على حمايـة الكائنـات الحيـة الدقيقـة المكونـة لتراكيب -C الستروماتولايت من الاستعمار من قبل كائنات أخرى.

وقد اشار (Browne et al.,2000 ; Blatt et al.,1980) إلى ان معظم الستروماتولايت يقتصر تواجده على الحجر الجيري النقي كما انه ممكن ان يتواجد احياناً في بعض أنواع السليكا أو المتبخرات. ان حفر الأحياء

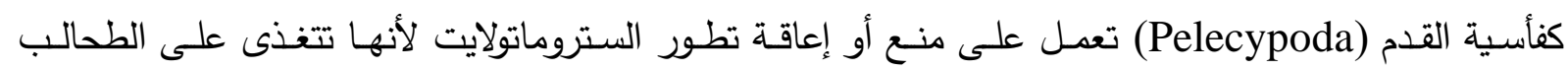

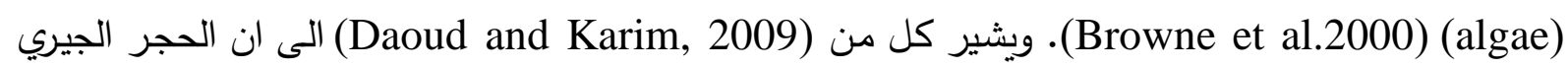
الرقائقي والحجر الجيري الكتلي ينتميان غالباً إلى الستروماتولايت الطحلبي.

\section{السحنات والبيئة الترسيبية:}

عرف (Miall, 1985) السحنة على أنها أجزاء محددة من وحدات طباقية معينة تُظْرُ صفات رسوبية وحياتية تميزها عن بقية الأجزاء. أظهرت الدراسة الرسوبية المفصلة للتكوين بوجود أربع سحنات مجهرية (وقسمت ونات

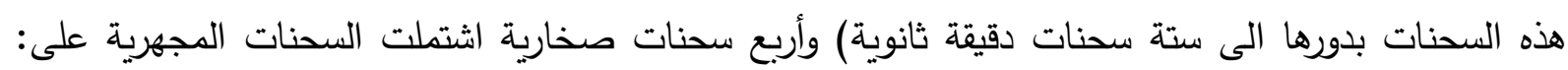
سحنة الحجر الجيري المترابط، سحنة الحجر الطيني والتي بدورها قست الى: سحنة الحجر الجيري الطيني اللامستحاثي الثانوية الدقيقة (M1) لوحة (D-3)، سحنة الحجر الجيري الطيني الحاوية على الفتاتات الاحيائية الثانوية الدقيقة (M2) لوحة (E-3)، سحنة الحجر الجيري الطيني الحاوية على الفورامنيفرا القاعية الثانوية الدقيقة (M3) الإحيائي الثانوية الدقيقة (W1)، (F-3)، سحنة الحجر الجيري الواكي الحاوية على الفتات الداخلي الثانوية الدقيقة لوحة (W2)، (G-3) ،وسحنة الحجر الجيري المرصوص وقسمت الى سحنة الحجر الجيري المرصوص الدملقي الثانوية الدقيقة لوحة (P1)، (H-3). فضلا عن السحنات الصخارية التي تم تشخيصها حقليا وهي السحنة الصخارية للستروماتولايت المستوي (L1) الصورة (6) والسحنة الصخارية للستروماتولايت المتموج (L2) الصورة (3،3) والسحنة الصخارية للستروماتولايت المتطبق (L3) الصورة (6) والسحنة الصخارية

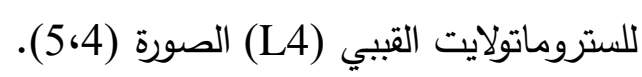
إذ يتم استنباط البيئة الترسيبية للتكوين قيد الدراسة، وذلك من خلال دراسة أنواع التراكيب الرسوبية ومن اهم التراكيب الرسوبية المشخصة هي تراكيب الستروماتولايت والمكونات الحبيبية والأنسجة المجهرية والحشود الحياتية وطبيعة توزيعها فضلاً عن طبيعة السحنات الرسوبية وصولاً إلى الموديل الرسوبي. كما تتطلب عملية استتتاج البيئة الرسوبية معرفة كل من الدلائل الرسوبية والدلائل الحياتية وريطها معا من اجل التوصل إلىهيل إلى البيئة الترسيبية 
للتكوين قيد الدراسة، إذ تشير نتائج التحليل السحني الاقيق إلى ان التكوين ترسب في بيئات المسطحات المدية (Tidal Flat)

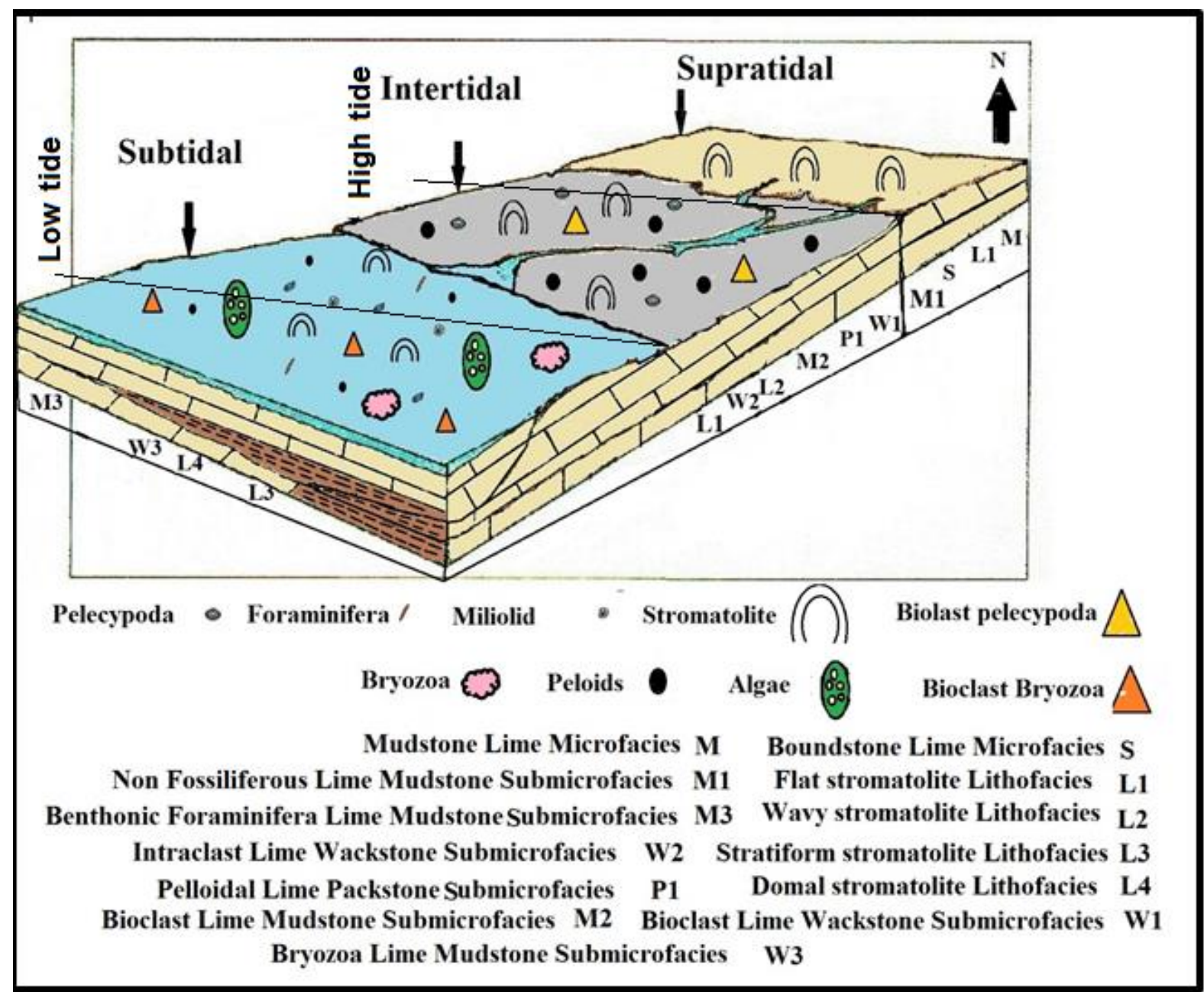

الشكل 6: بوضح الموديل الرسوبي لتكوين بارسرين في مقاطع الدراسة الحالية

\section{الاستنتاجات}

من خلال الدراسة الحالية تبين أن صخور الستروماتولايت الجيرية لتكوين بارسرين في المقاطع المدروسة

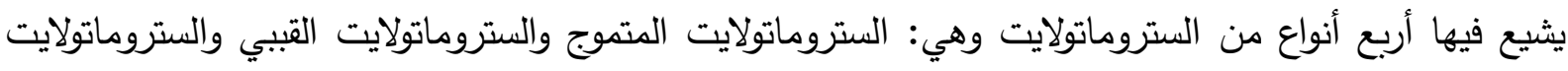
المستوي والستروماتولايت المتطبق. وبالاستعانة بالسحنات الصخرية للستروماتولايت والسحنات الرسوبية الدقيقة تبين أن تكوين بارسرين مترسب ضمن بيئة المسطحات مدية بأقسامه الثلاث الفوق مدية والبين مدية والتحت

يتواجد تركيب الستروماتولايت في بيئات مختلفة مثل بيئة الرصيف القاري (Shelf) وبيئة المسطحات

المدية (Tidal flat) بالإضافة إلى تواجده في بيئة السبخة (Sabkha) والممالح (Salina) (-) Wilson,1975) Browne et al.,2000). وتثير أغلب الدراسات إلى أن الستروماتولايت يكون شائع في البيئات الرسوبية 
الضحلة، وفي الوقت الحالي فأن انتثاره يكون مقيداً بسبب انتثار وتطور الكائنات الحية التي تقترس الأحياء المكونة للستروماتولايت (Farias et al.,2011,2013; Reid et al.,1995). وقد اشار (Hoffman,1976) إلى ان الستروماتولايت المستوي يتثكل في بيئات بين المدية (Intertidal) وان كلا من الحجر الجيري الرقائقي

والحجر الجيري الكتلي يترسب في بيئتي البين المدية (Intertidal) وتحت المدية (Subtidal) على التوالي. أن العوامل المسيطرة على توزيع وتصنيف الستروماتولايت الحديث في البيئات بين المدية (Intertidal) والبيئات تحت مدية (Subtidal) في المياه البحرية المفتوحة وفقا لـ (Walter,1976):

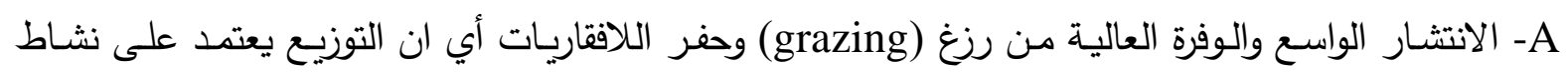
الاحياء المغذية للطحالب مقابل او نسبة لنشاط التعكر الحياتي. -B مدى فعالية تاثير السمنتة السريعة بسبب نشاط الكائنات الحية والتراكيب الرسوبية العضوية. وقد اشار كل من (Logan et al.,1964;Aitken,1967) إلى ان الستروماتولايت يتأثر تأثراً شديداً

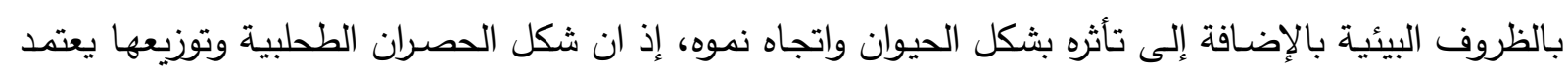

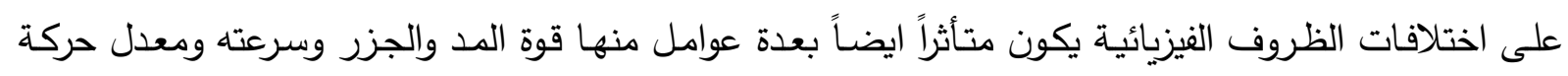
الرواسب على القاع. كما ان الستروماتولايت ممكن ان يتكون في البيئات المديه ذات الطاقة الواطئة أي من الجزيء

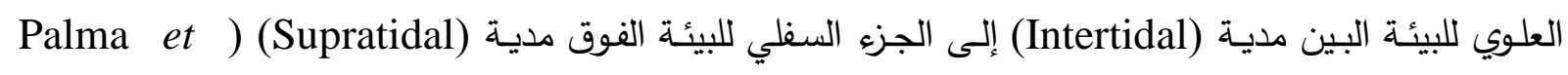
2015.al., أن الستروماتولايت قاوم كل الظروف الصعبة التي مرت بتاريخ الكرة الأرضية حيث انه يكون شائع في حقبة ماقبل الكامبري (Proterozoic،Archean) ، إلى الوقت الحاضر ، الا انه في الوقت الحالي يكون شائعاً في البيئة بين المدية (Subtidal) (Sutertidal) والبيئة تحت المدية (Smith et al.,2018).

\section{تصنيف الستروماتولايت Classification of stromatolite}

هناك عدة تصانيف للستروماتولايت منها تصنيف العالمان (Fledmann \& Mckenze,1998) حيث صنفا الستروماتولايت بالاعتماد على الأحياء الحقيقة النواة مثل الطحالب (Algae) المسجلة في تتابعات التكوين (اللوحة F-1). في حين يعتمد تصنيف (Aitken,1967) على وصف الأشكال المستوية من الستروماتولايت، بينما يعتمد تصنيف (Logan et al.,1964) على وصف الأشكال الكروية والثبه كروية من الستروماتولايت وقد

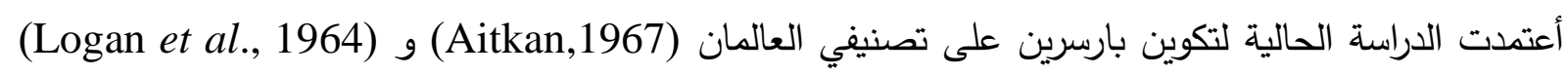
كما في الثكل (6)، وقد سجلت الدراسة الحقلية في مقاطع التكوين قيد الدراسة الأصناف التالية:

\section{A}

يعتبر من أكثر الأنواع الثائعة في تكوين بارسرين ويتميز بانه عبارة عن رقائق موجية متتاوبة. أو يطلق

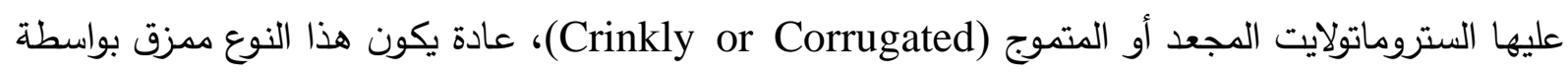
التشققات الطينيـة (desiccation cracks)، والفجوات الطولانيـة (elongate cavities)، والمسـامية اللوزيـة (Stow,2005) (laminar fenestrae) مدية (Intertidal) في مناخ جاف (Illing et al.,1965; Kinsman and Park,1976). ويوجد هذا النوع 
في الاجزاء السفلى والوسطى للمقطع النموذجي والاجزاء السفلى في كل من مقطع ساركلو ومقطع رانية. وقد تم تشخيص هذا النوع مجهرياً (اللوحة A-3).

B الستروماتولايت المستوي (Flatt stromatolite):

وهو عبارة عن صفائح رقيقة يشبه هذا النوع من الستروماتولايت الستروماتولايت المتموج من ناحية

التصفح أو الترقق والمكونات المعدنية، الا انه يختلف عنه بعدم احتوائه على جيوب حبس الغاز هذا يعود

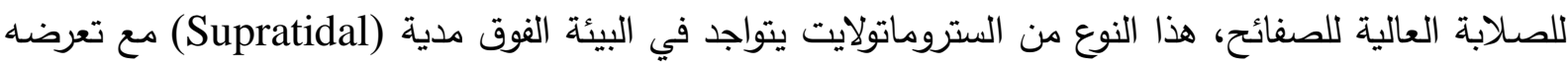
لفترات طويلة للانكشاف (Kendall and skipwith,1968). وقد يطلق عليه ايضا الرقائق الطحلبية الخفية (Flugel ,1982; Stow ,2005). ويظهر هذا النوع في الأجزاء العليا والوسطى من المقطع النموذجي والأجزاء العليا في كل من مقطع رانية ومقطع ساركلو. وقد تم تشخيص هذا النوع مجهريا (اللوحة B-3).

C الستروماتولايت القببي (Domal stromatolite): يتميز هذا النوع من الستروماتولايت بان اشكاله تكون شبه دائرية ومترابطة جانبيا (Laterally) ارتباطا وثيقا. أو عبارة عن رقائق مجعدة شبه مستمرة بين القبب الفردية (Stow,2005). ويوجد هذا النوع في البيئة بين مدية إلى تحت المدية (Intertidal to shallow subtidal) ويعتبر من الأنواع المميزة لـ (Shark Bay) غرب (a) استراليا (Logan et al.,1964). ويوجد هذا النوع في الاجزاء العليا في كل من المقطع النموذجي والأجزاء الوسطى من مقطع ساركلو ومقطع رانية. وقد تم تشخيصه مجهرياً (اللوحة C-3).

(Stratiform Stromatolite) الستروماتولايت المتطبق): وهـو عبارة عن رقائق مستقيمة مستمرة متعاقبة مـع رقائق تختلف عنهـا بـاللون والتركيب، حيث ان الستروماتولايت المتطبقة تعطي دليلاً مباشراً على البيئة تحت المدية وقد شخص هذا النوع الأجزاء السفلى في كل من المقطع النموذجي ومقطع ساركلو ومقطع رانية الصورة (6).

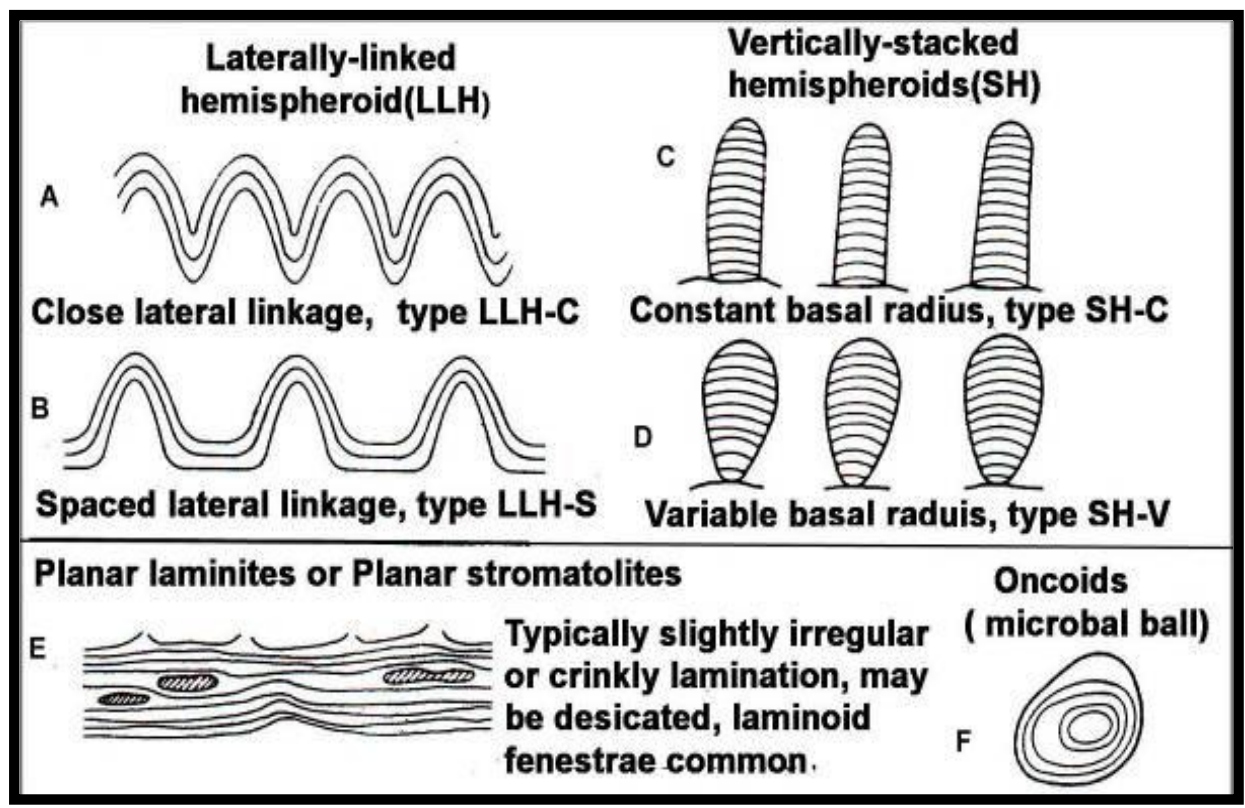

الثكل 6: يوضح تصنيف الستروماتولايت حسب (Logan et al., 1964). 


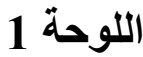
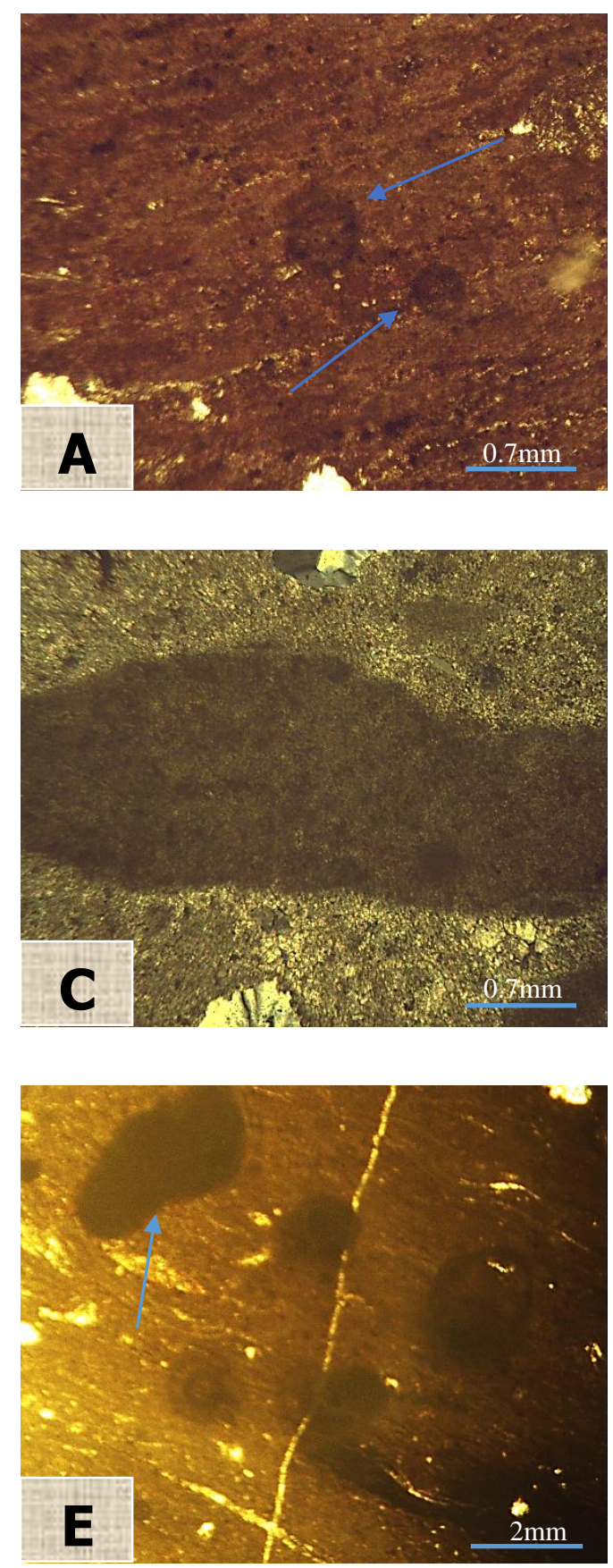
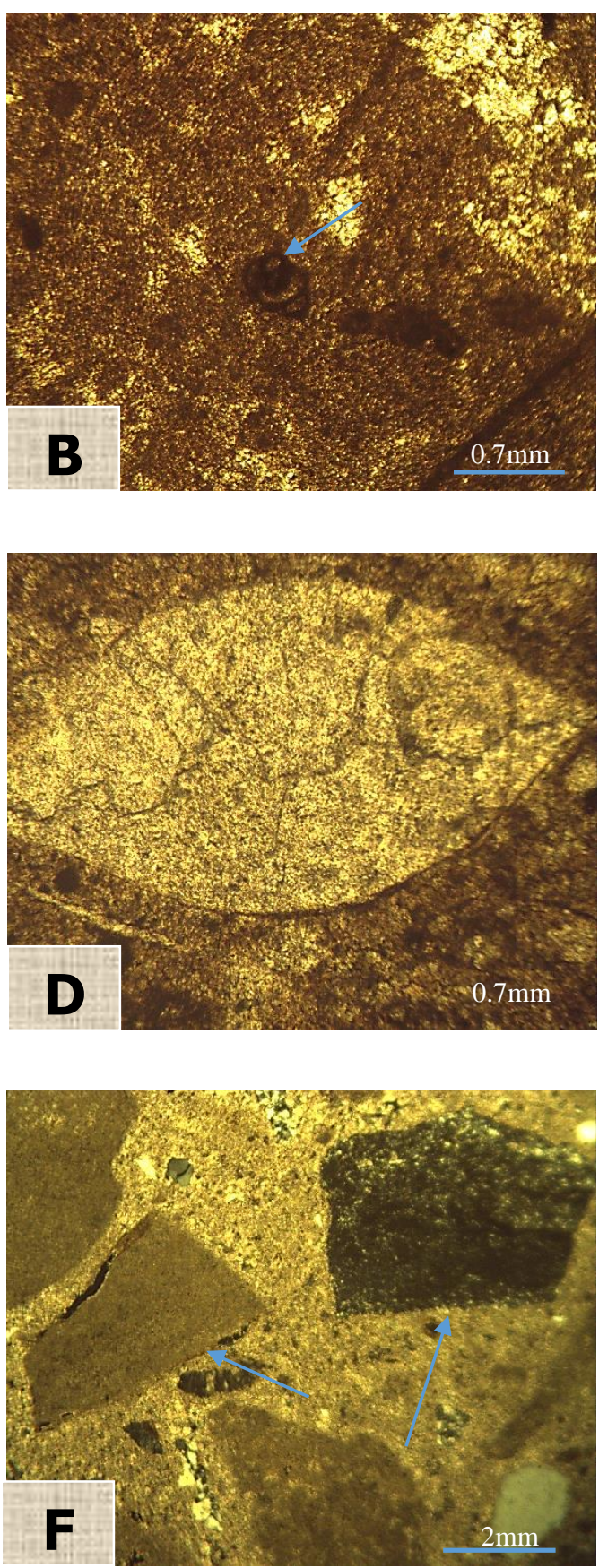

A B. صدفة الفورامنيفرا القاعية الجنس (Quinquiloculina)، وسحنة الحجر الجيري الطيني الحاوية على (Naulis الفورامنيفرا القاعية الثانوية الدقيقة.

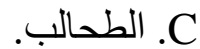
D. Dدفة فأسية القدم Pelecypoda) كاملة.

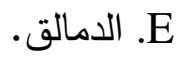
F فتاتات داخلية ، فتاتات خارجية. 


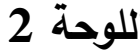
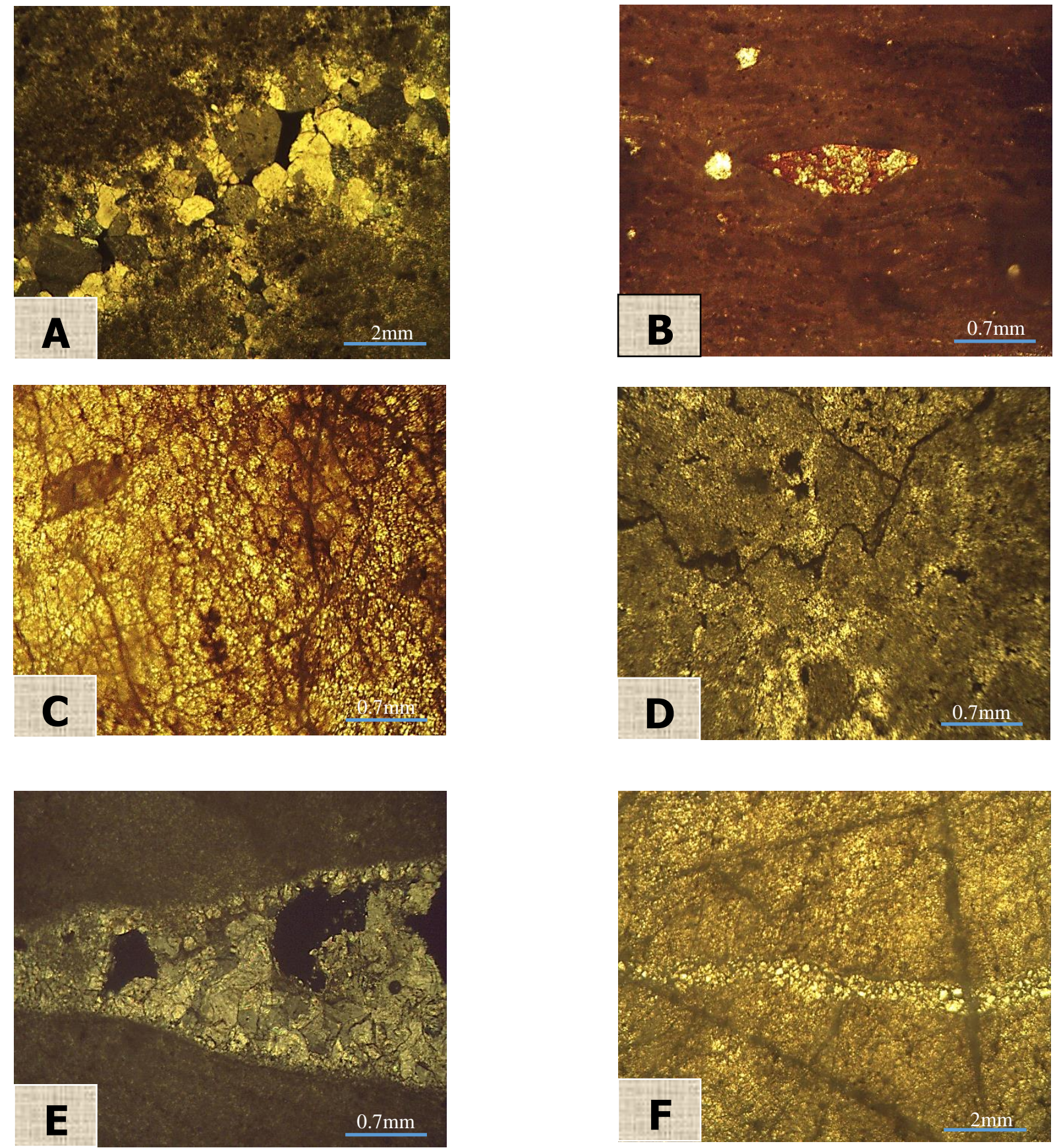

$$
\text { A }
$$

B. صدفة فأسية القدم حدث بها اذابة واحلال معدن الهيمتايت.

C C C الانضغاط الفيزيائي.

D D. الانضغاط الكيميائي. D.

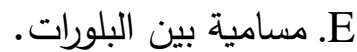

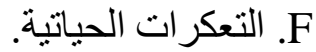




\section{اللوحة}
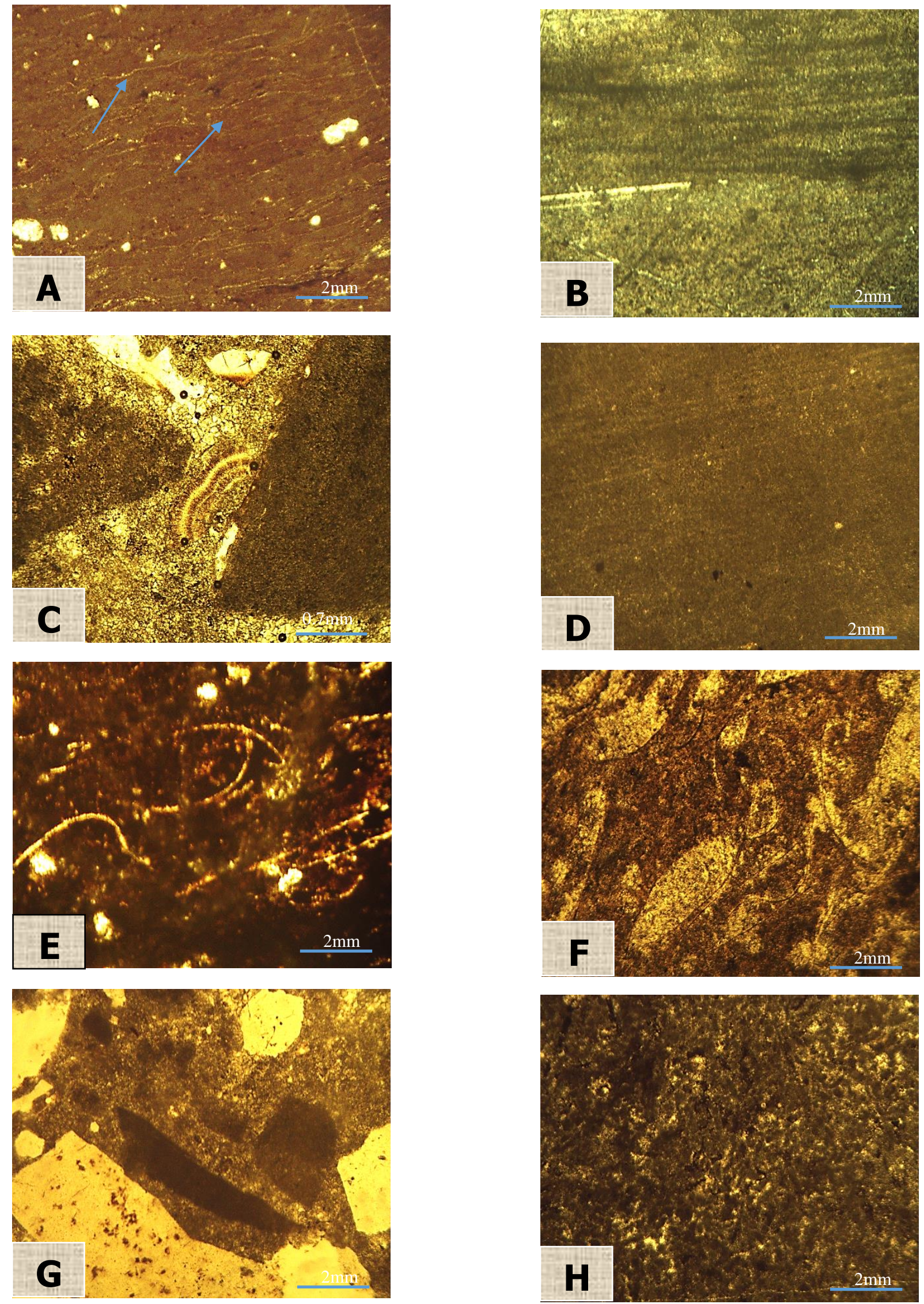

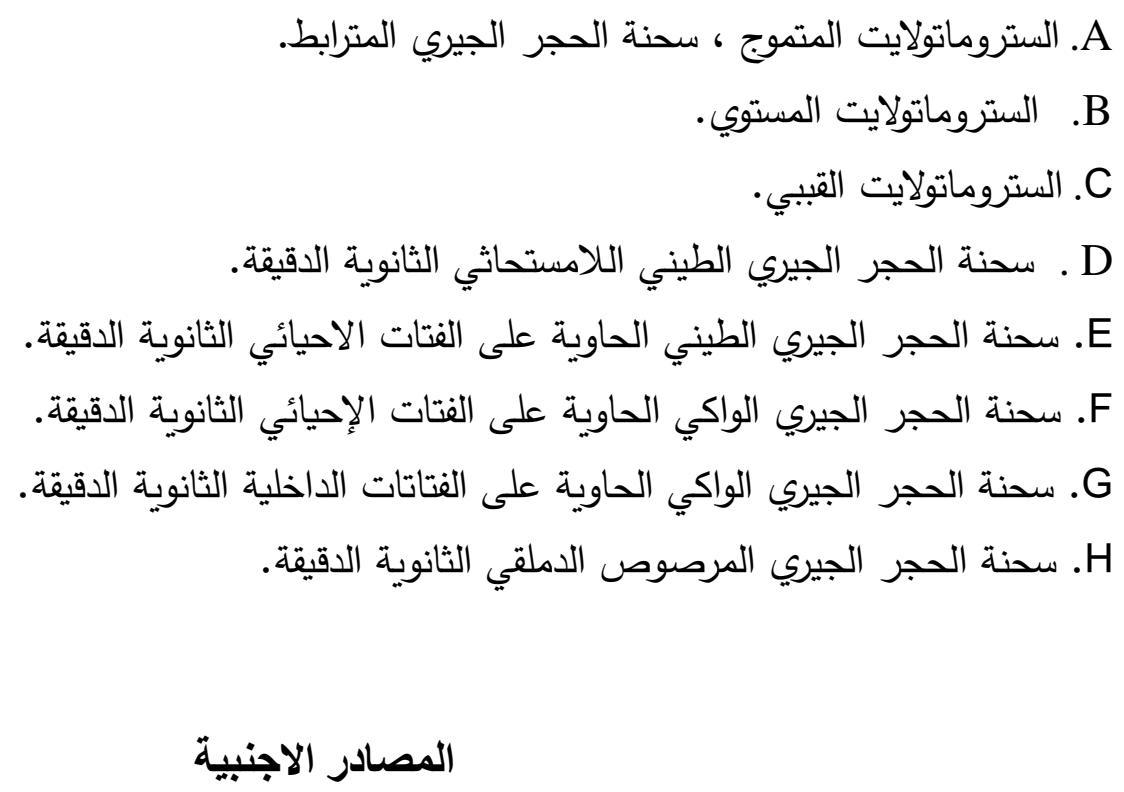

Aitken, J.D., (1967): Classification and environment significance of cryptalgal limestone and dolomites, with illustrations from the Cambrian and Ordovician of Southwestern Alberta. Jour. Sed. Pet. Vol.37, No.4.pp.1163-1178.

Bellen, V.R.G., Dunnington, H.V., Wetzel, R. and Morton, D.M., (1959): Lexique Stratigraphic International. Vol.3, Asie Fascicule loa-Iraq. Paris, 333p.

Blatt, H., Middleton, G. and Murray, R. (1980): Origin of Sedimentary Rocks. Prentice-Hall, USA. 782 p.

Bosak, T., Knoll, A.H., and Petroff, A.P., (2013): The meaning of stromatolites: Annual Review of Earth and Planetary Sciences, Vol. 41, pp. 21-44.

Browne, K. M., Golubic, S., and Seong-Joo, L., ( 2000): Shallow marine microbial carbonate deposits. In Riding,R. and Awramik, M. (Eds), Microbial Sediments, Springer-Verlag, p. 233-249.

Daoud, H.S. And Karim, K.H, (2009): Type of stromatolite in the Barsarin Formation (Late Jurassic), Barazanja area, Northerneast Iraq. Iraqi Bulletin of Geology and Mining, Vol. 6, No. 1, pp. 47-57.

Farias, M.E., Poiré, D.G., Arrouy, M.J., Albarracin, V. H., (2011): Modern Stromatolite ecosystems at alkaline and hypersaline high altitude lakes in the Argentinean Puna. In: Tewari V, Seckbach J (eds) Stromatolites: interaction of microbes with sediments. Springer Netherlands, Dordrecht, pp .427-441.

Farias, M.E., Rascovan, N., Toneatti, D.M., Albarracin, V.H., Flores, M.R., Poiré,D.G., Collavino, M.M., Aguillar, M., Vazquez, M.P. and Polerecky, L. (2013) Thediscovery of stromatolites developing at $3570 \mathrm{~m}$ above sea level in a highaltitudevolcanic Lake Socompa, Argentinean Andes. PLoS One 8 (1), e53497. 
Feldmann, M, and McKenzie, J. A., (1998): Stromatolite-Thrombolite associationsin a modern environment, Lee Stocking Island, Bahamas. Palaios: April1998:Vol,13,No.2, pp.201 -212.SEPM, Society for Sediments Geology.

Flugel, E., (1982): Microfacies of Limestone, Christenson, K. (Translator), SpringerVerlag, Berlin, 633p.

Grotzinger, J.P., and Rothman, D.H., (1996): An abiotic model from stromatolite morphogenesis. Nature, Vol. 383, pp. 423-425.

Hoffman, P., (1976): Stromatolite morphogenesis in Shark Bay, Western Australia. In: Walter, M.R. (ed.). Stromatolites. Developments in Sedimentology vol. 20, Elsevier, Amsterdam, pp. 261- 271.

Illing, L.V., Wells, A.S. and Taylor, J.C.M. (1965): Penecontemporary dolomite in the Persian (Arabian) Gulf. In: Pray, L.C. and Murray, R.C. (eds.). Dolomitization and limestone diagenesis: a symposium- SEPM special pub. No.13, pp. 89-111.

Jassim, S.Z. and Buday, T., (2006): Late Tithonian-Early Turonian Megasequence AP8: In Jassim, S.Z. and Goff, J.C. (eds) Geology of Iraq. Published by Dolin, Prague and Moravian Museum, Brno. pp.124-154.

Kendall, C.G.St.C. and Skipwith,P. A .D E., (1968): Recent algal mats of a Persian (Arabian) Gulf lagoon. Jour. of Sed. Petr.Vol.38,pp.1040-1058.

Kinsman, D.J.J. and Park, R.K., (1976): Algal belt and coastal sabkha evolution, Trucial coast, Persian (Arabian) Gulf. In: Walter, M.R. (ed.). Stromatolites. Developments in Sedimentology Vol. 20, Elsevier, Amsterdam, pp. 421-433.

Logan, B.W., Rezak, R. and Ginsburg, R.N., (1964): Classification and environmental significance of algal stromatolite. Jour. Geol. Vol. 72, pp. 68-83.

Lowe, D.R., (1994): Abiological origin of described stromatolites older than 3.2 Ga. Geol., Vol. 22, pp. 387-390.

Mata, S.A., and Bottjer, D.J., (2012): Microbes and mass extinctions paleoenvironment distribution of microbialites during times of biotic crisis. Geobiology, Vol.10, pp.3-24.

Meyers, S.R., and Peters, S.E., (2011): A 56 millionyear rhythm in North American sedimentation during the Phanerozoic: Earth and Planetary Science Letters, Vol. 303, pp. 174-180.

Miall, A.D. (1985): Principle of Sedimentary Basin analysis, Springer \&Verlag, Berlin, 490p.

Palma, R.M., Kietzmann, D.A., Comerio,M., Chivelete, M.C., Gomez, J.L., Bressan, G.S.,(2015): Oxfordian microbial laminites from La Manga Formation, Ne uquen Basin , Argentina: Remarkable nanobacteria preservation.Jour. of Iberian , Geol. , Vol.41, no.3, pp.351-363. 
Reid, R. P., Macintyre, I. G., Steneck, R. S., Browne, K. M., and Miller, T. E., (1995): Stromatolites in the Exuma Cays, Bahamas: Uncommonly Common, Facies, Vol. $33,1-18$.

Riding, R., (1994): Stromatolite survival and change: The significance of Shark Bay and Lee Stocking Island subtidal columns. In: Krumbein, E., Patterson, D.M. and Stal, L.J. (eds.). Biostabilization of sediments. Verlag, Berlin pp. 183-202.

Smith, A., Cooper A., Misra,s., Bharuth,V., Guastell,L. and Botes,R., (2018): The extant shore platform stromatolites (SPS) Facies association : a glimpse into the Archean. Biogeosciences, Vol.15, pp. 2189-2203.

Stow, D.A.V., (2005): Sedimentary Rocks in the field A colour Guide. Manson Publishing, UK, 320p.

Walter, M.R. (ed.)., (1976): Stromatolites. Elsevier, Amsterdam. 790 p.

Warren, L.V., Varejao, F.G., Quaglio, F., Simoes, M.G., Fursich, F.T., Poire, D.G., Catto,B., Assine, M.L.,(2016): Stromatolites from the Aptian crato Formation, a hypersaline lake system in the Araripe Basin, northeastern Brazil. Facies, Vol.63, No.3, pp. 1-19.

West, I.M., (2003): Geology of the Wessex Coast, Southern England, [http://www.soton.ac.uk/ imw/index.htm], Accessed May 4, 2005.

Wilson, J.L. (1975): Carbonate facies in geologic history. Springer-Verlag, Berlin. 471 p. 